\title{
MODELLING OF ACTIVE SUSPENSION SYSTEM FOR QUARTER CAR (PID CONTROL, MATLAB)
}

\author{
Danish Saifi \\ M. tech (CAD - CAM) \\ Galgotias University, Greater Noida, \\ Uttar Pradesh 203201, India
}

\author{
Mr. Pramod Kumar \\ Department of Mechanical Engineering \\ Galgotias University, Greater Noida, \\ Uttar Pradesh 203201, India
}

\begin{abstract}
We are discussing active suspension in this research. It also includes an actuator or controller (ECU), wheels and body. The rider feels comfort in travelling due to the use of these types of suspension. Because it controls vertical moments or moves of the wheels and stable rider or passenger. It is most important in the automobile industries. There are many types of controllers used for fine control to vibration caused by wheels. E.g., PID controllers, it stands for Proportional Integral Derivative. PID controller provides better simultaneous vibration of the output of the control loop. It also used for improving the performance of the suspension system. We can do modelling and simulation carried out in MATLAB software for active suspension.
\end{abstract}

Keywords - proportional integral derivative, ECU.

\section{INTRODUCTION}

With the help of an active suspension system, the framework is to isolate the vehicle body from road disorders for smooth comfort. Also too as well performs the most important function of connecting the car body and tires. Also, there are many some components included like springs, dampers, linkages. Due to the use of the damper, it absorbs energy and also reduces the damp vibrancy.

Researchers have been trying for a long time to balance the car with the help of suspensions. Some factors attract the researcher such or like as stagnation, path holding and comfortable ride in various conditions. Nowadays, A Special type of spring or coil used in the automobile. But in 1920, Leyland Motors Utilized a torsion bar for a suspension system. In the 18th era beginning, a steel spring had been connected to the wagon by French.

There are three types of suspension systems used to control the Quarter-Car modal.
* Passive suspension system

* Active suspension system

* Semi-active suspension system

* Passive suspension system:

- In the passive suspension system, some component is fixed such as spring, damper etc.

- The passive suspension system is also used for better comfort riding.

* Active suspension system:

- In active suspension system, spring and damper are replaced by control force.

* Semi-active suspension system:

- The semi-active suspension is also used in an automobile which controls damping force.

- We can also customize the damping coefficient.

\section{PURPOSE}

My purpose is to make a batter active suspension system with the help of which we can control my system. My target is also to achieve setting time less than 7 second and overshoot have to reduce less than $5 \%$ in my suspension system.

\section{MODELLING OF ACTIVE SUSPENSION SYSTEM}

The active suspension system consists of sprung and unsprang mass. Sprung mass displays car 
body. And unsprang mass (suspension mass) including tire or wheel. The wheel is also represented parallel spring in the active suspension system.

In the figure shows, "x" represents the vertical position of a car body, " $\mathbf{y}$ " represents the upward position of the suspension system and "R" represents the upward position of the road.

\begin{tabular}{|c|c|c|c|}
\hline S.N. & Symbols & Unit and data & parameters \\
\hline 1 & Mc & $2065 \mathrm{~kg}$ & Mass of car body \\
\hline 2 & Ms & $305 \mathrm{~kg}$ & Suspension mass \\
\hline 3 & $\mathbf{Z 1}$ & $70000 \mathrm{~N} / \mathrm{m}$ & $\begin{array}{l}\text { spring for suspension } \\
\text { system }\end{array}$ \\
\hline 4 & $\mathbf{Z 2}$ & $500000 \mathrm{~N} / \mathrm{m}$ & Spring for wheel \\
\hline 5 & D1 & $450 \mathrm{~N}-\mathrm{s} / \mathrm{m}$ & $\begin{array}{c}\text { Damper for } \\
\text { suspension system }\end{array}$ \\
\hline 6 & D2 & $16500 \mathrm{~N}-\mathrm{s} / \mathrm{m}$ & Damper for wheel \\
\hline 7 & $\mathbf{F}$ & $\mathbf{N}$ & Control forces \\
\hline
\end{tabular}

Table - 1 Data used for modelling for an active suspension system

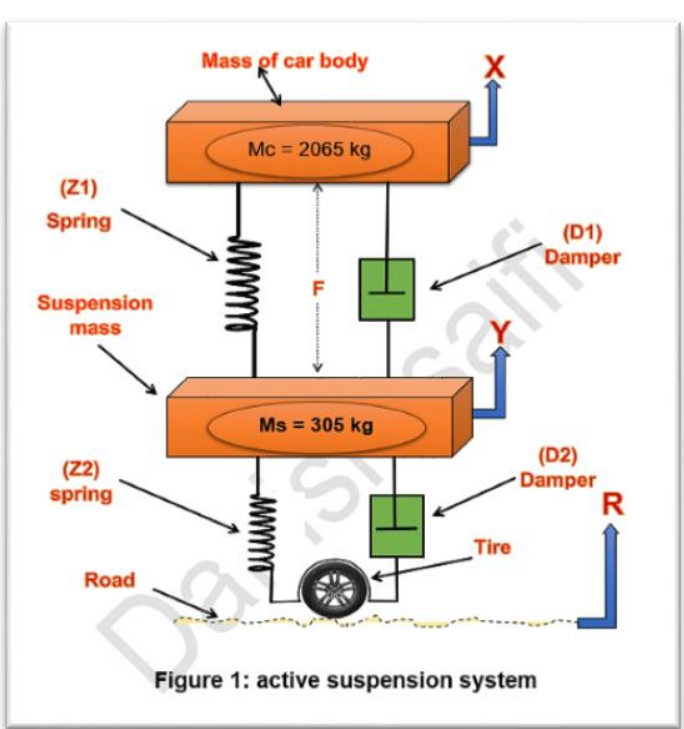

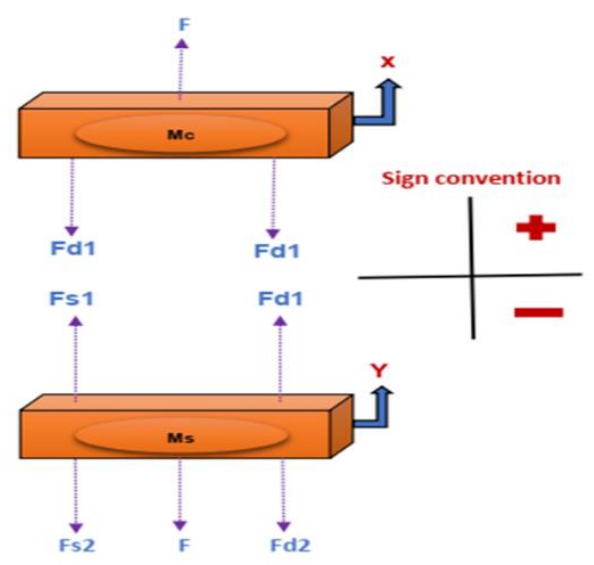

Fig. 2. Free body diagram

Assumptions:

- $(x, y)$ is coordinate

- Let $\mathrm{x}=0, \mathrm{y}=0$ when system is in static equilibrium.

We can obtain equation of motion by Newton's law of motions

For Mc (mass of the car body):

$\mathrm{Z1}(\mathrm{x}-\mathrm{y})=\mathrm{Fs} 1$

$\mathrm{D} 1\left(\mathrm{x}^{\cdot}-\mathrm{y}^{*}\right)=\mathrm{Fd} 1$

For Mc (suspension mass):

$\mathrm{Z} 2(\mathrm{y}-\mathrm{r})=\mathrm{Fs} 2$

$\mathrm{D} 2\left(\mathrm{y}^{\circ}-\mathrm{r}\right)=\mathrm{Fd} 2$

We know that

$\sum \mathrm{F}=\mathrm{ma}$

Mass 1:

$$
\sum \mathrm{F}=-\mathrm{Fs} 1-\mathrm{Fd} 1+\mathrm{F}
$$

Putting the value of Fs1 and Fd1 in equation of (5), we get

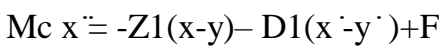

Mass 2: 
$\sum \mathrm{F}=\mathrm{Fs} 1+\mathrm{Fd} 1-\mathrm{Fs} 2-\mathrm{Fd} 2-\mathrm{F}$

Putting the value of Fs1, Fd1, Fs2 and Fd2 in equation of (7), we get

Ms y“ $=\mathrm{Z} 1(\mathrm{x}-\mathrm{y})+\mathrm{D} 1(\mathrm{x}-\mathrm{y})-\mathrm{Z} 2(\mathrm{y}-\mathrm{r})-\mathrm{D} 2\left(\mathrm{y}^{-}-\mathrm{r}\right)-\mathrm{F}$ (8)

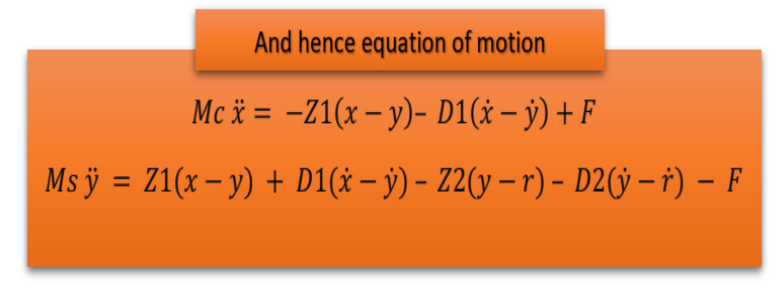

All initial conditions are zero

Taking Laplace in equation (6) and (8) on both sides

From equation (6), we get

$\left.\mathrm{Mc} \mathrm{L} \llbracket\left(\mathrm{d}^{\wedge} 2 \mathrm{x}(\mathrm{t})\right) / \llbracket \mathrm{dt}\right) \wedge^{\wedge} 2 \rrbracket=-\mathrm{Z} 1 \mathrm{~L} \llbracket \mathrm{x}(\mathrm{t}) \rrbracket+\mathrm{Z} 1$

$\mathrm{L} \llbracket \mathrm{y}(\mathrm{t}) \rrbracket-\mathrm{D} 1 \mathrm{~L} \llbracket(\mathrm{dx}(\mathrm{t})) / \mathrm{dt} \rrbracket+\mathrm{D} 1 \mathrm{~L} \llbracket(\mathrm{dy}(\mathrm{t})) / \mathrm{dt} \rrbracket+$

$\mathrm{L} \llbracket \mathrm{F}(\mathrm{t}) \rrbracket$

Then

$\mathrm{Mc} \llbracket \mathrm{s}^{\wedge} 2 \cdot \mathrm{X}(\mathrm{s})-\mathrm{s} \cdot \mathrm{X}(0)-(\mathrm{dx}(\mathrm{t})) / \mathrm{dt} \rrbracket=$

$-\mathrm{Z} 1 . \mathrm{X}(\mathrm{s})+\mathrm{Z} 1 . \mathrm{Y}(\mathrm{s})-\mathrm{D} 1 \llbracket \mathrm{s} . \mathrm{X}(\mathrm{s})-\mathrm{X}(0) \rrbracket+\mathrm{D} 1 \llbracket \mathrm{s} . \mathrm{X}(\mathrm{s})-$ $\mathrm{x}(0) \rrbracket+F(s)$

Therefore,

$\mathrm{X}(\mathrm{s}) \llbracket \mathrm{Mc} . \mathrm{s}^{\wedge} 2+\mathrm{Z} 1+\mathrm{D} 1 . \mathrm{s} \rrbracket=\mathrm{Y}(\mathrm{s}) \llbracket \mathrm{Z} 1+\mathrm{D} 1 . \mathrm{S} \rrbracket+\mathrm{F}(\mathrm{s})$

And from equation (8), we get

$\left.\operatorname{MsL} \llbracket\left(d^{\wedge} 2 \mathrm{y}(\mathrm{t})\right) / \llbracket \mathrm{dt}\right) \wedge 2 \rrbracket=\mathrm{Z} 1 \mathrm{~L} \llbracket \mathrm{x}(\mathrm{t}) \rrbracket-\mathrm{Z} 1 \mathrm{~L} \llbracket \mathrm{y}(\mathrm{t}) \rrbracket$ $+\mathrm{D} 1 \mathrm{~L} \llbracket(\mathrm{dx}(\mathrm{t})) / \mathrm{dt} \rrbracket-\mathrm{D} 1 \mathrm{~L} \llbracket(\mathrm{dy}(\mathrm{t})) / \mathrm{dt} \rrbracket-\mathrm{Z} 2 \mathrm{~L} \llbracket \mathrm{y}(\mathrm{t}) \rrbracket+$ $\mathrm{Z} 2 \mathrm{~L} \llbracket \mathrm{r}(\mathrm{t}) \rrbracket-\mathrm{D} 2 \mathrm{~L} \llbracket(\mathrm{dy}(\mathrm{t})) / \mathrm{dt} \rrbracket+\mathrm{D} 2 \mathrm{~L} \llbracket(\mathrm{dr}(\mathrm{t})) / \mathrm{dt} \rrbracket-$ $\mathrm{L} \llbracket \mathrm{F}(\mathrm{t}) \rrbracket$

And therefore

$\mathrm{Y}(\mathrm{s}) \llbracket \mathrm{Ms} \cdot \mathrm{s}^{\wedge} 2+(\mathrm{Z} 1+\mathrm{Z} 2)+\mathrm{s}(\mathrm{D} 1+\mathrm{D} 2) \rrbracket=$ $\mathrm{X}(\mathrm{s}) \llbracket \mathrm{Z} 1+\mathrm{D} 1 . \mathrm{S} \rrbracket+\mathrm{R} \llbracket \mathrm{Z} 2+\mathrm{D} 2 . \mathrm{s} \rrbracket-\mathrm{F}(\mathrm{s})$

Mathematical modelling has been completed. In which two forces act vertically to balance the entire system.
The two equations explained here.

\section{$\mathrm{X}(\mathrm{s}) \llbracket M c . s^{2}+Z 1+D 1 . s \rrbracket=\mathrm{Y}(\mathrm{s}) \llbracket \mathrm{Z1}+\mathrm{D} 1 . \mathrm{s} \rrbracket+\mathrm{F}(\mathrm{s})$}

$\left.Y(s) \llbracket M s . s^{2}+(Z 1+Z 2)+s(D 1+D 2) \rrbracket=X(s) \llbracket Z 1+D 1 . S \rrbracket+R \llbracket Z 2+D 2 . s\right]-F(s)$

\section{PROCESS AND RUNNING BY PID CONTROLLER}

PID control is a type of feedback control system which control the dynamic system and it is connected between sprung and unsprung mass. It uses three types of parameters proportional, integral and derivative. With the help of these parameters, we can get better stability. Get better stability we can tune the parameters.

Fig. 3. PID controller with feedback

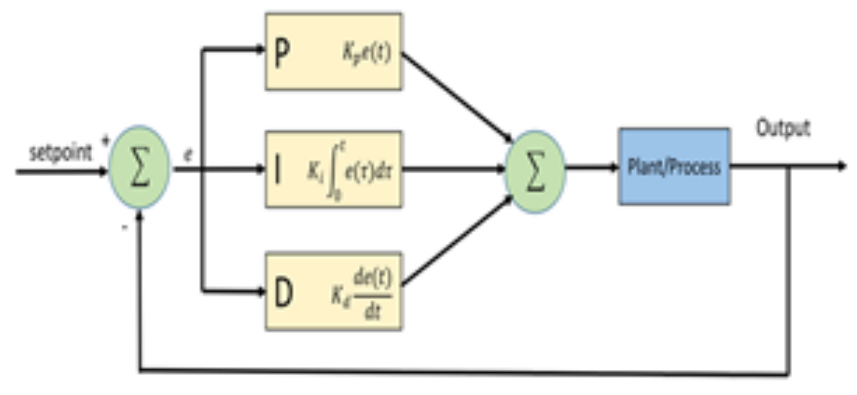

\begin{tabular}{|c|c|c|c|}
\hline Control response & \multicolumn{2}{c}{ Kp } & \multicolumn{2}{c|}{ Ki } \\
\hline Rise time & decrease & decrease & Small change \\
\hline overshoot & increase & increase & decrease \\
\hline $\begin{array}{c}\text { Steach state } \\
\text { error }\end{array}$ & decrease & eliminate & No change \\
\hline Setting time & Small change & increase & decrease \\
\hline
\end{tabular}

Table -2 PID controller activity

For better tuning we considered value like

$\mathrm{Kd}=208025 ; \mathrm{Kp}=832100 ; \mathrm{Ki}=624075$. 


\section{RESULTS AND DISCUSSION}

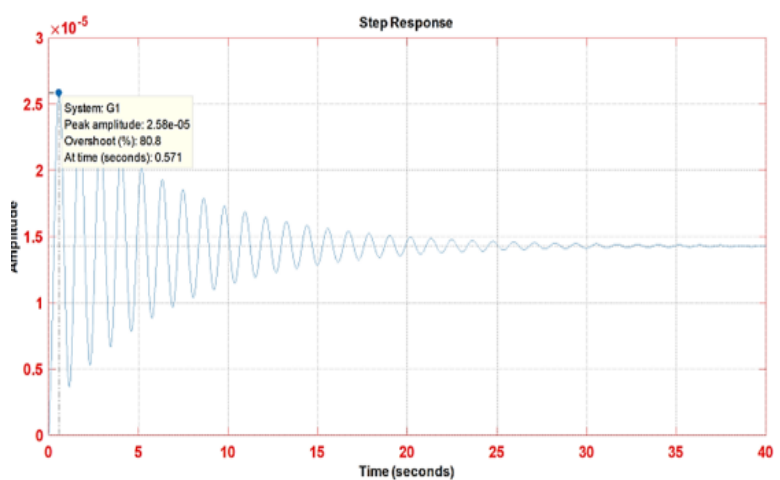

Fig. 4. This graph represents car body mass (Mc) response

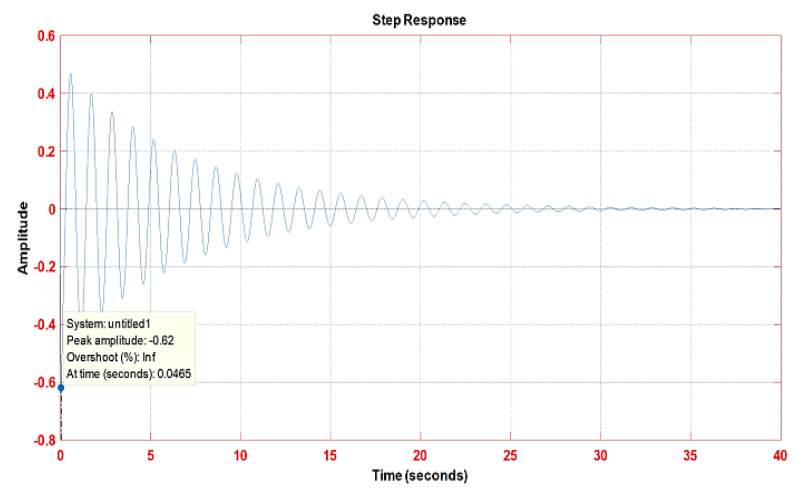

Fig. 5. This graph represents suspension system (Ms) response

In Fig 4. When we give a small amount of actuating force in the absence of feedback control. The figure shows that the open-loop system is an underdamped condition. Due to this response passenger feels a small amount of vibration. which lasts a long time.

In Fig5. The response of $10 \mathrm{~cm}$ steps disturbance, in the open-loop graph. when Quarter-Car moves over the $10 \mathrm{~cm}$ road bump. we can see that the quarter car oscillates for a long time of about 40 seconds. when we give initial amplitude of $8.5 \mathrm{~cm}$. Due to these conditions' passenger feel bizarre motion.
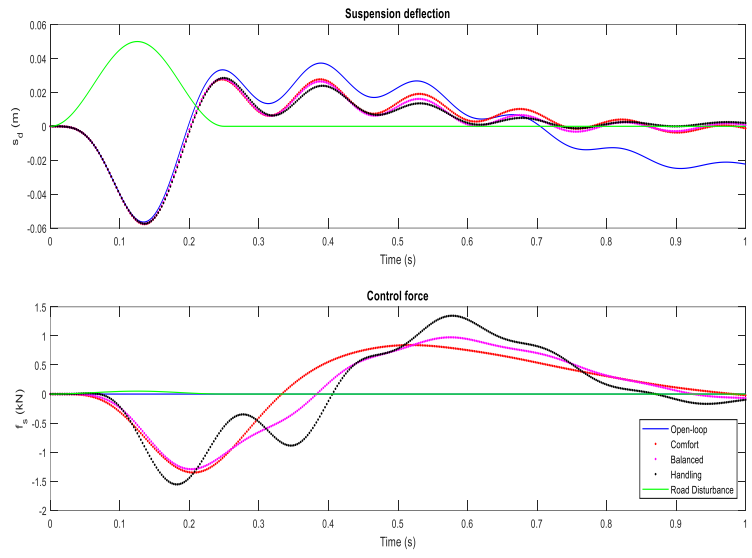

Fig. 6. Suspension deflection and control force

In Fig 6. We can see in the graph body acceleration is less than controller emphasizing. And a large controller indicates suspension deflection.

From the balanced system, we get a better understanding between the body increasing speed and suspension deflection

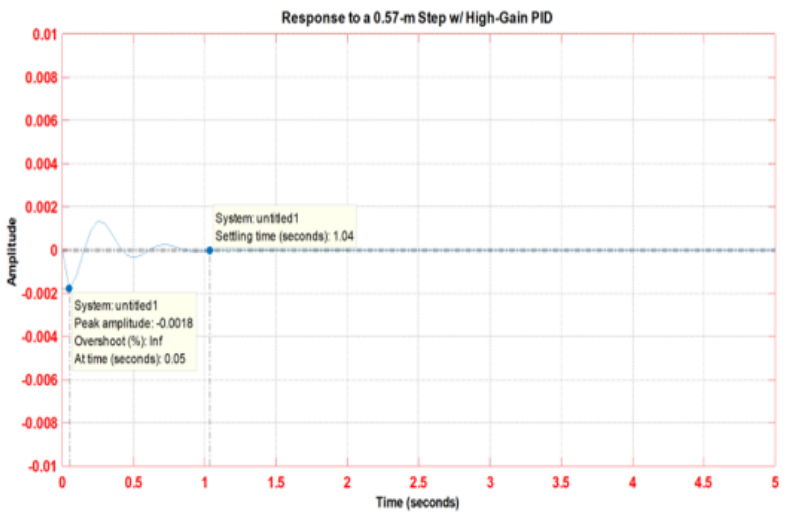

Fig. 7. Response to a $0.57 \mathrm{~m}$ step w/ high gain PID

In Fig 7. We can see in the above figure the setting time is 1.04 second is less than 7 second and overshoot also less than $5 \%$. 


\section{International Journal of Engineering Applied Sciences and Technology, 2021 \\ Vol. 5, Issue 10, ISSN No. 2455-2143, Pages 155-160 \\ Published Online February 2021 in IJEAST (http://www.ijeast.com)}

\begin{tabular}{|c|c|c|}
\hline Characteristics & Results & Final results \\
\hline $\begin{array}{c}\text { Peak response } \\
\text { (overshoot) }\end{array}$ & $\mathbf{8 0 . 8 \%}$ & $\mathbf{5 \%}<\mathbf{8 0 . 8 \%}$ \\
\hline $\begin{array}{c}\text { Settling time } \\
\text { Rise time }\end{array}$ & $\mathbf{2 6}$ seconds & $\mathbf{1 . 0 4}<\mathbf{7}$ seconds \\
\hline Steady state & $\mathbf{0 . 2 2 6}$ seconds & $\mathbf{0}$ seconds \\
\hline & $\mathbf{1 . 4 3 e - 0 5}$ & $\mathbf{0}$ seconds \\
\hline
\end{tabular}

Table -3 . Final result of active suspension system

\section{CONCLUSION}

- The above data is correct. If we make an active suspension system with the data, we get better stability.

- we can see that in the above graph overshoot is less than $5 \%$ and the settling time is 1.04 .

\section{REFERENCES}

[1] Avesh, M., \& Srivastava, R. (2012, March). Modeling simulation and control of active suspension system in Matlab Simulink environment. In 2012 Students Conference on Engineering and Systems (pp. 1-6). IEEE.

[2] Sunwoo, M., Cheok, K. C., \& Huang, N. J. (1991). Model reference adaptive control for vehicle active suspension systems. IEEE Transactions on industrial electronics, 38(3), 217-222.

[3] Sharp, R. S., \& Crolla, D. A. (1987). Road vehicle suspension system design-a review. Vehicle system dynamics, 16(3), 167-192.

[4] Wu, S. J., Wu, C. T., \& Lee, T. T. (2005, June). Neural-network-based optimal fuzzy control design for half-car active suspension systems. In IEEE Proceedings. Intelligent Vehicles Symposium, 2005. (pp. 376-381). IEEE.

[5] Eski, I., \& Yildırım, Ş. (2009). Vibration control of vehicle active suspension system using a new robust neural network control system. Simulation Modelling Practice and Theory, 17(5), 778-793.

[6] Lin, J., \& Lian, R. J. (2010). Intelligent control of active suspension systems. IEEE Transactions on industrial electronics, 58(2), 618-628.

[7] Kumar, M. S. (2008). Development of active suspension system for automobiles using PID controller.
[8] Priyandoko, G., Mailah, M., \& Jamaluddin, H. (2009). Vehicle active suspension system using skyhook adaptive neuro active force control. Mechanical systems and signal processing, 23(3), 855-868.

[9] Qiu, J., Ren, M., Zhao, Y., \& Guo, Y. (2011). Active fault-tolerant control for vehicle active suspension systems in finite-frequency domain. IET control theory \& applications, 5(13), 1544-1550.

[10] Wang, G., Chen, C., \& Yu, S. (2017). Robust nonfragile finite-frequency $\mathrm{H} \infty$ static output-feedback control for active suspension systems. Mechanical Systems and Signal Processing, 91, 41-56.

[11] Wendel, G. R., \& Stecklein, G. L. (1991). A regenerative active suspension system (No. 910659). SAE Technical Paper.

[12] Gysen, B. L., van der Sande, T. P., Paulides, J. J., \& Lomonova, E. A. (2011). Efficiency of a regenerative direct-drive electromagnetic active suspension. IEEE transactions on vehicular technology, 60(4), 1384-1393.

[13] Zheng, X. C., Yu, F., \& Zhang, Y. C. (2008). A novel energy-regenerative active suspension for vehicles. Journal of Shanghai Jiaotong University (Science), 13(2), 184-188.

[14] Rao, M. V. C., \& Prahlad, V. (1997). A tunable fuzzy logic controller for vehicle-active suspension systems. Fuzzy sets and systems, 85(1), 11-21.

[15] Fateh, M. M., \& Alavi, S. S. (2009). Impedance control of an active suspension system. Mechatronics, 19(1), 134-140.

[16] Sam, Y. M., Osman, J. H., \& Ghani, M. R. A. (2004). A class of proportional-integral sliding mode control with application to active suspension system. Systems \& control letters, 51(3-4), 217-223.

[17] Jin, T., Liu, Z., Sun, S., Ren, Z., Deng, L., Yang, B., ... \& Li, W. (2020). Development and evaluation of a versatile semi-active suspension system for highspeed railway vehicles. Mechanical Systems and Signal Processing, 135, 106338.

[18] Deshpande, V. S., Shendge, P. D., \& Phadke, S. B. (2016). Nonlinear control for dual objective active suspension systems. IEEE transactions on intelligent transportation systems, 18(3), 656-665.

[19] Talib, M. H. A., \& Darns, I. Z. M. (2013, April). Self-tuning PID controller for active suspension system with hydraulic actuator. In 2013 IEEE 
Symposium on Computers \& Informatics (ISCI) (pp. 86-91). IEEE.

[20] Ghazaly, N. M., \& Moaaz, A. O. (2014). The future development and analysis of vehicle active suspension system. IOSR Journal of Mechanical and Civil Engineering, 11(5), 19-25.

[21] Cao, J., Li, P., \& Liu, H. (2010). An interval fuzzy controller for vehicle active suspension systems. IEEE Transactions on Intelligent Transportation Systems, 11(4), 885-895. 